\title{
EPIGRAFÍA DEL PAISAJE EN EL ANÁLISIS DE LA MATERIALIDAD FUNERARIA
}

\author{
Landscape Epigraphy in the Analysis of Funerary Materiality
}

\author{
Rodrigo Cabrera \\ cabrera.pertusatti@gmail.com \\ Universidad de Buenos Aires / CONICET. Argentina \\ María Laura lamarino \\ mlauiamarino@gmail.com \\ Universidad de Buenos Aires / CONICET. Argentina \\ Liliana M. Manzi \\ Im_manzi@yahoo.com.ar \\ Universidad de Buenos Aires / CONICET. Argentina
}

Resumen: En el presente trabajo, proponemos estudiar la dimensión funeraria a través de representaciones iconográficas y descripciones sobre la provisión de ofrendas en relación con las instituciones políticas (templos y palacios) y la administración estatal de Ur en Mesopotamia y de Tebas en Egipto, considerando los lugares en el paisaje, valorando tanto sus propiedades físicas como ponderando sus aspectos intangibles. A tal fin, nos focalizamos en un abordaje que se sustenta en el análisis de documentos que refieren a espacios funerarios, pero destacando también aspectos concernientes a su producción, distribución y almacenamiento. De este modo, enfatizamos elementos relativos a sus contextos sistémicos y sus caracteres semánticos (o componentes internos). Por tal motivo, a esta perspectiva de análisis, la denominamos Epigrafía del Paisaje y puede ser pensada en paralelo a la de "materialidad del signo lingüístico», la cual sostiene que la escritura puede considerarse una materialidad que recrea el universo de las relaciones sociales, al reunir en la modalidad de textos e iconografías, intervenciones culturales y representaciones mentales con los lugares seleccionados en el espacio regional. Para ello, se contempla una tripartición del paisaje entre humanos, lugares y objetos haciendo foco en: ( $a$ ) las prácticas, $(b)$ los agentes intervinientes y $(c)$ las espacialidades reconocibles.

Palabras clave: Epigrafía del Paisaje; materialidad funeraria; Mesopotamia; Egipto. 
Abstract: In this paper, we propose to study the funerary dimension through iconographic representations and descriptions about the provision of offerings in relation to political institutions (temples and palaces) and the state administration of Ur in Mesopotamia and Thebes in Egypt, considering the places in the landscape, valuing both its physical properties and weighing its intangible aspects. To this end, we focus on an approach that is based on the analysis of documents that refer to funeral spaces, but also highlighting aspects concerning their production, distribution, and storage. In this way, elements related to their systemic contexts and their semantic characters (or internal components) are emphasized. For this reason, we call this analysis perspective Landscape Epigraphy and it can be thought of in parallel to that of «materiality of the linguistic sign», which maintains that writing can be considered a materiality that recreates the universe of social relations, by bring together in the modality of texts and iconographies, cultural interventions, and mental representations with the selected places in the regional space. To do this, a tripartition of the landscape between humans, places, and objects is contemplated, focusing on: $(a)$ practices, $(b)$ agents, and $(c)$ spatialities.

Keywords: Landscape Epigraphy; funerary materiality; Mesopotamia; Egypt.

Sumario: 1 Introducción. 2. Interpretaciones sobre el paisaje y sus contribuciones para nuestra perspectiva. 3. Metodología 4. Estudios de caso. 4.1. Mesopotamia. 4.2. Egipto. 5. Agentes, espacios y prácticas en la dimensión funeraria. 6. Discusión. 7. Referencias bibliográficas.

\section{INTRODUCCIÓN}

En el presente trabajo, analizaremos los paisajes funerarios correspondientes a Ur (Mesopotamia) durante el período neo-sumerio (ca. 2110-2003 a. C.) y a Tebas (Egipto) en el Reino Nuevo (ca. 1550-1070 a. C.), a partir de una perspectiva analítica que denominamos «Epigrafía del Paisaje», en la cual se integran enfoques dirigidos al estudio de la «materialidad» (Miller, 2005) y la «textualidad» (Chartier, 2004) de los documentos referidos a la provisión de ofrendas funerarias. Dicho concepto también puede ser discutido en paralelo al de "materialidad del signo lingüístico», tópico que propusimos para analizar los sistemas de escritura del Próximo Oriente antiguo (Cabrera y Manzi, 2018; Cabrera, 2019a) y que alude a las formas de producción y procesamiento de información, y a sus modalidades de comunicación a través de la lógica de lo abstracto y el pensamiento concreto (sensu Lévi-Strauss, 1962) al integrar aspectos míticos con prácticas específicas.

Una discusión inicial con respecto a los sistemas de escritura del Próximo Oriente antiguo ha sido propuesta por Jan Assmann (1994, p. 15), al sostener que la materialidad de los signos tiene la capacidad para erigirse en un conjunto referencial del «mundo» que existe más allá de la escritura en sí. La escritura nace a partir de los objetos y de los eventos a los que refiere y alude a "cosas", independientemente de los sonidos y de las abstracciones que surgen de la lengua. De esta manera, adherimos a la idea de que la función primaria de la escritura no sería fonémica, 
sino más bien conceptual al etiquetar y nombrar entidades concretas (Eyre, 2018, p. 2).

Por otro lado, la materialidad del signo lingüístico se asemeja a la noción de "objetivación» hegeliana, la cual señala que, al fabricar objetos, las personas se constituyen a sí mismas a través del proceso. A propósito de esto, pensamos que la objetivación es un proceso de significación y, por lo tanto, la cultura material es susceptible de ser analizada por medio de una perspectiva semiótica (Preucel, 2006). De este modo, el registro arqueológico contempla narrativas a la manera de un texto (Tilley, 1990) y, por consiguiente, puede ser entendido como un conjunto de signos lingüísticos integrados a la cultura material.

Siguiendo esta línea analítica, escritura e iconografía constituyen una materialidad reconocible en tanto contenido activo de todo documento, comprendiendo la plasmación de mensajes impresos o grabados, las tecnologías de la escritura -papel, arcilla, papiro o piedra-y el soporte (Cabrera, 2017; 2019a; 2019b). Esto implica que se contemplen los soportes de la escritura y las prácticas sociales en las que se hallan inmersos, desde la preparación de las superficies para la plasmación de los textos hasta su posterior visualización, archivado y/o descarte (Piquette y Whitehouse, 2013, p. 3). Por consiguiente, en tanto elementos dinámicos del universo de relaciones sociales, se contemplan las condiciones de producción del mensaje como las ideas que se transmiten.

A partir de este marco de referencia, analizamos elementos epigráficos para la reconstrucción material e inmaterial de las prácticas mortuorias. A propósito, consideramos las ofrendas para entender la elección de lugares para el depósito del muerto como parte de los sistemas de creencias, en los cuales operan dimensiones: $a)$ sociales, referidas a las interacciones entre personas, y $b$ ) trascendentales, que posibilitan la integración de los difuntos en el más allá y con quienes renuevan las prácticas en el mundo terrenal. No solo se constatan a partir de adecuaciones específicas de sectores del paisaje y lugares, en el sentido de espacios funcional y simbólicamente definidos -en la conformación de necrópolis o cementerios-, sino que también existen referencias documentales directas e indirectas en cuanto a la circulación de bienes y las instituciones que las favorecen. Sin embargo, algunas de dichas referencias podrían contar con existencia comprobable, como es el caso de los registros administrativo-contables en tablillas de arcilla; otras constituirían una evocación, a partir de una selección y agrupamiento de rasgos concretos junto a otros imaginarios; $y$, finalmente, un conjunto de representaciones y menciones que aluden a lugares, objetos y sus cantidades, que podrían definirse como ficcionales.

En documentos egipcios y mesopotámicos, reconocemos este tipo de alusiones y observamos su plasmación en espacios específicos, tales como enterratorios, donde individuos y linajes entablan relaciones con instituciones del estado. Esto conduce a la conformación de paisajes funerarios, puesto que la organización del espacio responde a las especificidades de las prácticas mortuorias de la elite en 
diálogo con las acciones de los gobernantes y las instituciones del estado. Dichas observaciones motivaron a que propusiéramos la Epigrafía del Paisaje como una herramienta metodológica que nos permite analizar aquellas tres formas de representación -señaladas en el párrafo precedente-y sus respectivos componentes, es decir, si las mismas se presentan de forma concreta, concreta-abstracta o imaginaria.

De esta manera, a partir del análisis de un conjunto de iconografía e inscripciones cuneiformes y jeroglíficas, la Epigrafía del Paisaje posibilita el análisis de la incrustación de la dimensión funeraria para la discusión de sus contextos de producción, distribución y almacenamiento. Así, textos e imágenes pueden ser entendidos como representaciones «en/sobre/desde» el paisaje, que entablan relaciones con estructuras arquitectónicas particulares (tumbas, templos, palacios), dando cuenta de su materialidad (Miller, 2005) e inmaterialidad (Cabrera, 2020), en cuanto a su eficacia trascendental y como posibilitantes de invocación y evocación (Manzi, 2016) en la conexión de los humanos con la esfera divina.

\section{INTERPRETACIONES SOBRE EL PAISAJE Y SUS CONTRIBUCIONES PARA NUESTRA PERSPECTIVA}

En la actualidad, coexisten diversos enfoques que tienen como objetivo el estudio de las distribuciones de artefactos y estructuras, y, a través de los paisajes, de los sujetos y sus prácticas sociales, resultando de esas perspectivas una serie de conceptos importantes para nuestra propuesta. Algunas de esas posiciones han privilegiado aspectos vinculados con las escalas de análisis espaciales y temporales (Bailey, 2007; Binford, 2001; Butzer, 1982; Dincauze, 1987; Gamble y Soffer, 1990; entre otros) ${ }^{1}$, examinando capas de información, generalmente, a partir de las cronologías de dichos materiales (Criado Boado, 1999; Manzi, 2017; 2018).

En algunas instancias, se ha discutido cómo se distribuye el registro arqueológico haciendo referencia a la noción de yacimiento, ya sea como lugares de actividad (Binford, 1992) o bien como superficies en donde se disponen distintas cantidades de artefactos (Dunnell, 1992; Ebert, 1992; Foley, 1981). Incluso, en algunos casos, en los que se reconocía la existencia de yacimientos -micro-escala o escala local, independientemente de su acepción-, se planteó el estudio de las interrelaciones entre ciertas clases de evidencia, pero tomando a cada uno de ellos como la unidad de análisis (Belardi, 1992; Thomas, 1975), en vez de considerar a los yacimientos (Binford, 1991) como depositarios del conjunto de materiales.

${ }^{1}$ Sobre los temas tratados en esta sección, existe una extensa bibliografía, incluso más reciente. No obstante, preferimos citar a aquellos que iniciaron tales líneas de análisis. 
En la escala regional y más amplias aún -supra y mega-regional-, se ha planteado una gama diversa de enfoques, siendo posible sostener que existen tantas miradas como investigadores. Al introducir el concepto de paisaje, se han considerado perspectivas fisiográficas, a partir del reconocimiento de las distintas unidades geomorfológicas que lo conforman, atribuyéndoles distintas valoraciones por sus potencialidades de uso, sin descartar que parte de su elegibilidad también se sustenta en las connotaciones simbólicas otorgadas por los agentes humanos.

En un sentido foucaultiano, los paisajes son producto de relaciones de poder (Orejas, 1991; Criado Boado, 1993; Orejas, 1995; Criado Boado, 1999) que originan sus propios «mecanismos de representación». Coincidimos con Criado Boado (1999) en el reconocimiento de por lo menos tres dimensiones: $a$ ) el espacio en tanto entorno físico o medioambiental; $b$ ) el espacio como entorno social o medio construido; $y c$ ) el espacio como entorno pensado.

En este trabajo, entendemos por paisajes funerarios al juego de relaciones entre lugares, humanos y objetos para vincular el universo de los vivos con el de los muertos a partir de un conjunto pautado de prácticas sociales. En la selección de sitios, se debieron favorecer aquellos lugares o sectores que presentaban ciertas características o fisionomías aptas para el depósito de difuntos, la celebración de rituales funerarios y el culto a los antepasados. En tanto espacios liminales, se mantuvieron separados, aunque vinculados con los vivos, a pesar de su evitación a causa de cuestiones de salubridad y de la sustanciación de los misterios que se predicaban, a la vez que favorecieron la circulación de ofrendas y la evocación de personas e invocación de divinidades.

La especificidad que adquieren los paisajes funerarios radica en una forma de plasmación y perpetuación material e inmaterial luego de la muerte de un individuo $^{2}$, sea por el estatus o el papel desempeñado por este a partir de su supervaloración simbólica (First, 1961 [1938]; Blanton, 1965). Este pasaje trascendental implicaba la adopción de un rol post-mórtem, mediatizado por un conjunto de reglas sociales y lógicas parentales (Blanton et al., 1996; Feinman, 1995). En los casos que aquí analizaremos, la mencionada normativa y los vínculos parentales giran en torno a la provisión de ofrendas, sea por intercesión del templo, el palacio o el linaje. Se establecen así áreas de depósito específicas por su eficacia simbólica y/o por los cargos, estatus y linajes de los individuos (Hernando Gonzalo, 1999; Manzi, 2012; 2016; 2017b; Porter, 2002; 2007/2008; Rede, 2004; 2007).

Un cuerpo vivo es cognoscente de su finitud y, por tanto, es también un cuerpo potencialmente inerte que deberá tener su «morada final». En este sentido, se instaura un consenso acerca de cómo debe ser depositado de acuerdo con su posicionamiento social en un lugar especialmente seleccionado y sacralizado, a fin de

2 En algunas sociedades de cazadores-recolectores, esto guarda semejanzas con una forma de ancestralidad imaginaria mediada por prácticas totémicas (Descola, 2005). 
cumplir con rituales específicos y de crear estímulos sensoriales y simbólicos entre los vivos para con los difuntos, donde se despliegan además aspectos cultuales y de invocación/evocación de los propios y semejantes. En este contexto, objetos y estructuras, a la vez que existen y significan, adquieren la capacidad de permanecer periféricos y todavía ser determinantes de conductas e identidades (Miller, 2005, p. 5). De acuerdo a este último punto, todo objeto más allá de su manifestación real y, con ello, de su facultad de ser percibido, también puede simultáneamente ocultarse a los sentidos, pero aun así condicionar la visión que se posee sobre el mundo.

De este modo, se espera que la materialidad de lo mortuorio se constituya en un vehículo que remita a su inmaterialidad (Cabrera, 2020), a la vez que opere en el diálogo entre humanos, objetos y lugares dentro de un palimpsesto de temporalidades y espacialidades. En el plano existencial, consideramos que la configuración de paisajes funerarios es una expresión del dasein heideggeriano, al constituir una modalidad del ser-en-el-mundo y un estar-ahí como revelación del ser-para-la-muerte y manifestar la propia finitud del ser, la cual es materializada en un des-ocultamiento de aquello que se coloca como algo ajeno a lo «uno» (Heidegger, 1967 [1927]). Por ello, decodificar esta clase de paisaje, en un sentido semiótico, implica enfrentarse a la trama de la materialidad mortuoria en su contexto sistémico y entender su modo existencial integrado por la tríada sujeto/lugar/objeto. Así, la iconografía y la escritura como textos «en/sobre/desde» constituyen una Epigrafía del Paisaje que, en tanto formas de materialidad de la palabra y del pensamiento (Rodríguez Mayorgas, 2010, p. 11), se convierten en elementos palpables del entorno.

\section{METODOLOGÍA}

Nuestro abordaje acerca de la espacialidad funeraria hace foco en el estudio de los documentos, pero sin reducirlos a un análisis estrictamente filológico-semántico, centrado en aspectos descriptivos y sustentados en la traducción y la presentación del contenido que los conforma (discusión en Rodríguez Mayorgas, 2010, pp. 84-85; Tsouparopoulou, 2016), sino que, en cambio, se privilegia su estudio semiótico-sintáctico y sistémico, que enfatiza los aspectos contextuales de producción y conservación (ver ejemplos de análisis en van Essche-Merchez, 1992; Sence, 2007). Asimismo, la revalorización del concepto de epigrafía, tanto por su materia y forma como por su contenido, implica la integración de los entramados estructurales/contextuales como un aspecto central a estudiar en el reconocimiento de los lugares a los que los documentos remiten o implican.

En función de nuestro objetivo, se analizan los paisajes funerarios de Ur y Tebas a partir de una selección de inscripciones e iconografía. En el caso de Mesopotamia, se estudian tablillas administrativas e improntas de sellos cilindros, mientras que, en el caso de Egipto, se analizan inscripciones e iconografía, cuyos soportes son las 
paredes de tumbas. A través de estas clases de evidencias, puede observarse la configuración del entorno -físico/natural, social/construido y pensado/imaginado (sensu Criado Boado, 1999)- y sus referencias a lugares concretos, a los construidos con elementos de realidad y en parte idealizados, y/o aquellos que comprenden elementos exclusivamente ficticios e inmateriales.

Si bien la Epigrafía del Paisaje refiere a la interconexión entre humanos, objetos y lugares, dado que su principal desempeño como herramienta analítica es contribuir al estudio de contextos funerarios emergentes de la praxis social, su instrumentalización opera desde la materialidad a la inmaterialidad (Cabrera, 2019a; 2020). De este modo, nuestra propuesta apunta al análisis de la configuración de paisajes funerarios en registros documentales, desde un abordaje semiótico-estructural, que dé cuenta de la multidimensionalidad de espacios involucrados respecto de la provisión de ofrendas. Nos referimos a todos aquellos indicios materiales e inmateriales que estructuran la organización territorial, a través de la dotación y representación material y de las decisiones humanas para el desarrollo de prácticas rituales y la cimentación de áreas cultuales por medio de su sacralización (Manzi, 2012).

La tripartición conformada por acciones humanas, materialidades e inmaterialidades es de gran utilidad para pensar el entramado semiótico en el que se hallan inmersas inscripciones e iconografía, tanto desde el sentido epigráfico/sincrónico que implica la variable espacial como desde el paleográfico/diacrónico que señala la dimensión temporal. El entramado semiótico coincide con el contexto de producción, distribución y almacenamiento de los artefactos, reconociendo en relación a ellos: $(a)$ los agentes intervinientes, $(b)$ las prácticas y $(c)$ las espacialidades implícitas y explícitas (figura 1).

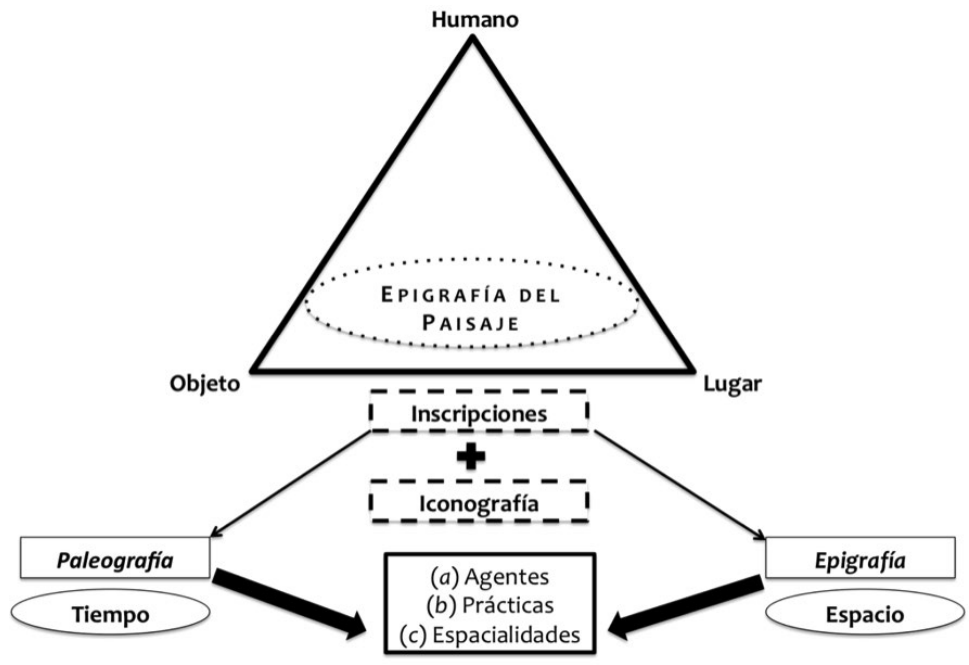

Figura 1 
La documentación administrativa mesopotámica aporta información substancial sobre diferentes prácticas sociales e, incluso, habilita a la reconstrucción de buena parte de las actividades cotidianas. En nuestro caso, para la comprensión y discusión de los paisajes funerarios, las tablillas administrativas se presentan como fuentes necesarias en la enumeración y descripción de los agentes humanos y suprahumanos e instituciones intervinientes, de los yacimientos y monumentos involucrados para la ejecución de las ceremonias y la provisión de los bienes/objetos empleados durante cada performance. El habitus de la documentación administrativa trae a colación un tipo de información que, si bien no está despojada de la ideología del momento, aporta una visión más próxima para la reconstrucción de las prácticas sociales.

Los textos administrativos pueden ser subdivididos de acuerdo con tipologías y subgéneros, y, en relación con este punto, pueden considerarse las tablillas selladas y no selladas. No obstante, el sellado cumplía una función burocrática desempeñada por un agente específico del ámbito público (Tsouparopoulou, 2015, pp. 11-12). Además, y aunque funcionara a modo de rúbrica, daba cuenta de la importancia de lo iconográfico en la tipología de inscripciones, a la manera de un «paratexto» (Tsouparopoulou, 2013, pp. 10-11), y, así, ponía de manifiesto la interconexión entre texto e imagen dentro del conjunto de prácticas y posibles secuencias de ejecución.

En el caso egipcio, se subraya la imposibilidad de disociar las inscripciones jeroglíficas de las representaciones iconográficas, ya que unas y otras se encuentran integradas (Tefnin, 1979; Tefnin, 1984; Hartwig, 2004). Estas relaciones pueden ser de concordancia, disyunción (Bryan, 1996) o discordancia (Angenot, 2002), sin embargo, texto e imagen se complementan en función del mensaje. Al mismo tiempo, operaba una fuerte superposición entre el embodiment material de un texto por medio de la escritura y su parte performativa-oral (Eyre, 2018, p. 10), la cual se expresaba como programa decorativo (van Essche-Merchez, 1992; Pereyra, 2012).

Las inscripciones e iconografía analizadas provienen de tumbas de la elite $y$, dada la abundante disponibilidad de fuentes, se propone analizar la provisión de ofrendas en el contexto de la Bella Fiesta del Valle. Las imágenes y los textos debieron cumplir no sólo un rol representativo, sino, en simultáneo, formaban parte del equipamiento ritual indispensable para las celebraciones que allí se realizaban. Consideramos que es posible que representaciones e inscripciones pudieron conformar, o bien el único, o bien la mayor parte del equipo funerario, el cual podía activarse mediante rituales y los difuntos ser eternamente provistos a través de la recitación de conjuros, creando un canal entre el mundo de los vivos y el inframundo. 


\section{ESTUDIOS DE CASO}

Considerando los contextos de producción de la documentación elegida para el estudio de Mesopotamia y Egipto, se habilita la discusión y comparación en cada caso del rol desempeñado por el templo -encarnación del poder religioso- y el palacio -personificación del poder secular- en relación a entierros de miembros de la elite.

\subsection{Mesopotamia}

El corpus de textos administrativos de la Tercera Dinastía de Ur comprende actualmente unos 120000 documentos, e incluye una serie de copias de tablillas que se conservan en diversos museos alrededor del mundo, colecciones privadas y registros de piezas robadas (Molina, 2008, p. 20, 2016, pp. 1-2, 2020, pp. 341-344). Los archivos disponibles, procedentes de la ciudad capital de Ur (Tell Muqejjir), registran unas 4297 tablillas, en tanto el resto se distribuye entre 26 yacimientos (cf. Molina, 2016, p. 8). Si nos centramos en los documentos que refieren a la construcción de capillas mortuorias y consideramos a la capital estatal, la ciudad de Ur, contamos con 19 para todo el período.

Los archivos provinciales aluden a las transacciones llevadas a cabo tanto a nivel local como en relación a la capital política. Asimismo, se desprende un corpus lexicográfico específico que estaba conectado con el ordenamiento burocrático, el cual fue el resultado de un proceso de reorganización del aparato político y la estructura socioeconómica durante el reinado de Šulgi, segundo monarca de la Tercera Dinastía de Ur. Uno de los elementos constitutivos de la burocracia estatal neosumeria fue el dominio absoluto y exclusivo de la escritura en tanto praxis social. De acuerdo a Piotr Steinkeller (2004, p. 79), la función de un texto administrativo consistía en hacer inteligible, incluso para una persona extraña a la gerencia estatal, la información que cada uno recogía.

En dicha época, la institucionalización política se configuró en torno a la hegemonía del poder real de la casa de Ur, a diferencia de la primera parte del tercer milenio a.C., cuando se había dado el predominio de la elite del templo en tanto gran organización del estado. Para revertir esto último, la institución del palacio se apropió de los dispositivos de control antes operados por el templo, algo de lo que ya se evidenciaba desde fines del Protodinástico Illb y se fortaleció en época sargónica (Laneri, 2008).

Las tablillas administrativas también comprenden la dimensión funeraria al aludir a la circulación de bienes, la construcción de espacios para la celebración de rituales y la evocación ceremonial de la memoria de los muertos, implicando el despliegue de una nueva materialidad (Porter, 2002; 2007-2008). Los términos conectados con los paisajes funerarios fueron $\mathrm{k} \mathrm{i}-\mathrm{a}-\mathrm{n}$ a $\mathrm{g}$ o «capilla mortuoria», cons- 
truida para el ritual de enterramiento y el culto mortuorio, y ki - $\mathrm{m}$ a h o «tumba» (Jagersma, 2007; Molina, 2019), para el depósito de los cadáveres, cuyos emplazamientos se erigieron en sitios de competencia con las grandes organizaciones (en particular, los templos) en cuanto al acaparamiento de bienes. Asimismo, la capilla funeraria y la tumba fueron lugares escogidos para la colocación de ofrendas, tanto en el momento liminal de la muerte y entierro de un individuo cuando se celebraba una ceremonia de lamentación llevada a cabo por determinados agentes rituales, como en la instancia de evocación póstuma de la memoria del difunto. Los bienes, que se depositaban en calidad de ofrendas y de los que se tiene un registro a partir de la evidencia epigráfica, se contabilizaban por medio de cifras concretas y en consonancia, en muchos casos, con otras transacciones que se inventariaban en los mismos documentos (Molina, 2016).

Del conjunto de información existente, se destacan, a los fines de este trabajo, las tablillas selladas procedentes de Ur, entre las cuales hay tres que mencionan al $\mathrm{ki}$ - a - n a $\hat{\mathrm{g}}$ y portan un tipo de sello conocido como «regalo real» o inaba a partir del reinado de Šulgi (Franke, 1977; Mayr y Owen, 2004: 145; Winter, 1986). Una de ellas, Nisaba 5-2, 110 (U. 31110), se encuentra en un deteriorado estado de conservación y, por tal motivo, sólo pueden leerse tres líneas, entre las que se menciona al $\mathrm{ki}$ - a - $\mathrm{n}$ a $\hat{\mathrm{g}}$, pero no podemos saber su datación. Las otras dos tablillas, UET 3, 242 (U. 4703) y UET 3, 252 (UM 47-29-58/U. 03790), están datadas respectivamente en el año 7 del reinado de Ibbì-Su'en, mientras que la otra en el mes 11 del año 8 del mismo monarca.

Dado que únicamente se ha preservado un único ejemplar en lapislázuli de un sello inaba y solo se los reconoce a partir de las improntas dejadas por los mismos (Mayr y Owen, 2004, p. 152; Tsouparopoulou, 2008, pp. 35-36), no podemos discutir su composición material. En los sellos inaba, se representaba, en la mayoría de los casos, a dos figuras: al monarca que se transformaba en el dador del objeto (y fuente primigenia de legitimidad) y al funcionario receptor del regalo (Mayr y Owen, 2004, pp. 153-154). Por medio de estas escenificaciones, el monarca se ubicaba en el centro del poder político.

Por otra parte, si bien las circunstancias de uso de los sellos inaba en la documentación administrativa del período no es del todo clara, es curioso que, en UET 3 , 242 (U. 4703) y UET 3, 252 (UM 47-29-58/U. 03790), el contenido de los documentos refiera a la entrega de ofrendas funerarias a los antepasados reales. A propósito, en UET 3, 242 (U. 4703), se observa lo siguiente:

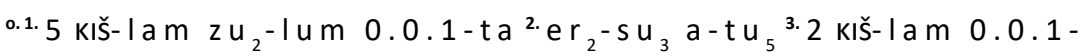
ta ${ }^{4 .} 8$ KIš-lam 5 sila $_{3}-t^{5}{ }^{5 .} \mathrm{ma}_{2}$ an-na-še ${ }_{3}{ }^{6 .} 6$ KIš-lam 5 sila ${ }_{3}$-ta ${ }^{\text {r.1. }}$

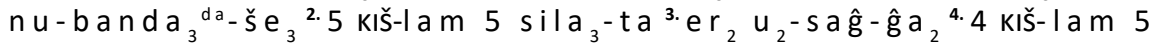

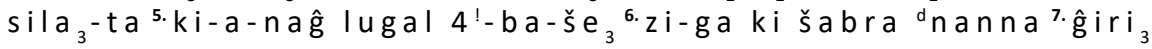

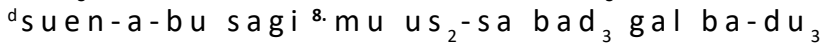




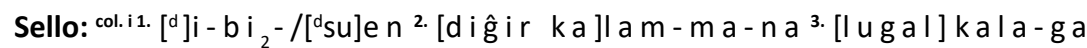
4. [lugal u]ri ${ }_{5} / \mathrm{ki}-\mathrm{ma}$ col.iil. I ugal an-ub-/da limmu ${ }_{2}$-ba-ke ${ }_{4}{ }^{2 . d}$ suen$a-b i_{2}{ }^{3 .} s a g i^{4} \cdot d u_{10}-u s_{2}-\left[a_{2}\right]^{5 .} n a m-d u m u-k a-n i-i r^{6} \cdot i n-n a-b a$

o. 1. 5 contenedores de dátiles de 10 litros cada uno ${ }^{2 .}$ (para) la lamentación (y) el ritual de purificación. ${ }^{3 .} 2$ contenedores (de dátiles) de 10 litros cada uno (y) ${ }^{4 .} 8$ contenedores (de dátiles) de 5 litros cada uno ${ }^{5}$. hacia el barco de An. ${ }^{6} .6$ contenedores (de dátiles) de 5 litros cada uno ${ }^{\text {r. 1. }}$ para el funcionario nubanda. ${ }^{2 .} 5$ contenedores (de dátiles) de 5 litros cada uno ${ }^{3 .}$ (para) una lamentación (y) un ritual de cosecha. ${ }^{4} 4$ contenedores (de dátiles) de 5 litros cada uno ${ }^{5}$ para la capilla funeraria de los 4 reyes. ${ }^{6}$. Expedido de parte del sacerdote šabra de Nanna ${ }^{7}$. por medio de Su'en-abu, el copero. 8. Año: 7 de Ibbī-Su'en.

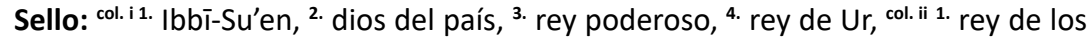
cuatro rumbos. ${ }^{2}$ A Su'en-abi, ${ }^{3 .}$ el copero, ${ }^{4}$. su compañero ${ }^{5}$. de la infancia, ${ }^{6}$ le dio (este sello).

En el anterior documento, por un lado, el contenido específico del texto detalla una serie de cantidades de dátiles que son colocadas en recipientes y son empleadas de manera particular durante ciertas performances rituales. Se mencionan dos lamentaciones, una purificación y una ceremonia vinculada a las cosechas. Todos los ritos eran realizados por especialistas a quienes les correspondía una remuneración de parte del estado por llevar a cabo dichas actividades cultuales. Asimismo, se hace referencia a una parte de los dátiles destinada a las capillas funerarias de cuatro reyes, seguramente, los antecesores de Ibbī-Su'en (Ur-Namma, Šulgi, AmarSu'ena y Šū-Su'en), a quienes se les rendía culto en Ur. Por otro lado, se señala al nubanda, el supervisor de las tareas de los trabajadores, y además se alude al šabra, encargado de la administración del templo.

Finalmente, se menciona al copero real, Su'en-abi, quien también aparece en el sello inaba que se encuentra sobre el documento, donde se lo nombra como "compañero de la infancia» de Ibbī-Su'en. De este modo, la participación del copero tanto en la inscripción de la tablilla propiamente dicha como en el sello, así como en la iconografía que acompaña a este último, resalta la importancia del funcionario dentro de la burocracia estatal del momento. El mismo sello se empleó en las tablillas Syracuse 210 (SUL 300) (cuya datación corresponde a los días 14 y 16 del mes 4 del año 1 de Ibbī-Su'en) y PDT 2, 916 (datada en el día 3 del mes 11 del año 2 de Ibbī-Su'en), ambas procedentes de Puzriš-Dagān. En efecto, Su'en-abi, no solo se desempeñó en el cargo de copero real sino que también en el sello inaba se lo menciona como "compañero de la infancia» del monarca y, en Syracuse 210, operó como maškim («notario»). 
El otro texto, UET 3, 252 (UM 47-29-58/U. 03790), datado en el año 8 de IbbīSu'en, también menciona la entrega de ofrendas con motivo del culto mortuorio de uno de los monarcas fallecidos, Amar-Su'ena:

0.1. $9 \mathrm{sila}_{3} \mathrm{i}_{3}-\hat{\mathrm{g} e s ̌}{ }^{2}$ iti ezem-mahn ${ }^{3.9} \mathrm{sila}_{3} \mathrm{i}_{3}$ - $\mathrm{g}$ e š ${ }^{4}$ iti ezem-anna ${ }^{5 .} \mathrm{ki}-\mathrm{a}-\mathrm{nag}$ damar-d suen-še ${ }_{3}{ }^{6 .} \mathrm{ki}$ ga-ti-e-ta ${ }^{\text {r. }}{ }^{1 .} \mathrm{kišib}$ Uri ${ }_{5}{ }^{\mathrm{ki}}-\mathrm{ki}-$

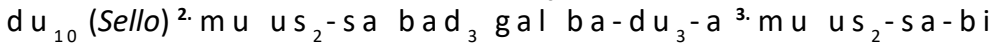

Sello: coli.i. di-bi ${ }^{-{ }^{d}}$ suen ${ }^{2}$ diĝ ir kalam-ma-/na ${ }^{3 .}$ lugal kala-ga ${ }^{4}$

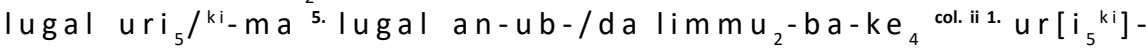

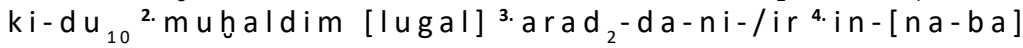

0.1. 9 litros de aceite de sésamo. ${ }^{2 .}$ Mes: $10 .{ }^{3 .} 9$ litros de aceite de sésamo. ${ }^{4}$ Mes: 11. ${ }^{5 .}$ Para la capilla mortuoria de Amar-Su'ena. ${ }^{6 .}$ De parte de Gati'e. ${ }^{\text {r. }}{ }^{1 .}$ Sellado por Urikidu. ${ }^{2}$ Año: 7 (y) ${ }^{3}$ año: 8 de lbbī-Su'en.

Sello: ${ }^{\text {col. i } 1 .}$ Ibbī-Su'en, ${ }^{2}$ dios del país, ${ }^{3 .}$ rey poderoso, ${ }^{4}$. rey de Ur, ${ }^{5}$ rey de los cuatro rumbos. ${ }^{\text {col. ii } 1 .}$ Para Uri-kidu, ${ }^{2}$ el cocinero, el rey, ${ }^{3 .}$ a su servidor, ${ }^{4}$. le dio (este sello).

En el anterior texto, se alude a la cantidad de aceite de sésamo utilizado para la capilla mortuoria de Amar-Su'ena y se hace referencia a Uri-kidu, un cocinero, quien recibió también un sello inaba, el cual además aparece en la tablilla BIN 3, 585, procedente de Puzriš-Dagān, pero que data del mes 5 del año 9 de Šū-Su'en. No obstante, tal como queda plasmado en el sello, Ibbī-Su'en lleva los títulos de «rey de Ur» y «dios del país», y, de este modo, en términos cronológicos, Šū-Su'en ya estaría muerto a pesar de ser nombrado por haber construido el templo del dios Šara en Umma en dicho nombre de año ( $m u$ ďs u- ${ }^{d}$ s u e n I u gal u ri ${ }_{5}{ }^{k i}-m a-k e_{4}$ $e_{2}$ ďara ${ }_{2} u m m a^{k i} m u-d u_{3}$ ).

De modo semejante, en PDT 1, 541, texto procedente de Umma y datado en el día 3 del mes 4 del año 9 de Amar-Su'ena, se hace mención del festival abum del mismo monarca, en cuyo momento se habría preparado dicho convite ceremonial. Por consiguiente, así como en PDT 1, 541 el rey Amar-Su'na ya habría fallecido, en BIN 3, 585, Šū-Su'en también estaría muerto, a pesar de que en los nombres de años figuren todavía como gobernantes de hecho (ver discusión en Steinkeller, 2008, p. 188 y nota 7). Mark Cohen (1993), en su análisis del calendario cúltico de Mesopotamia, sostiene que el vocablo a-bu-um («montículo para uso funerario») tendría su origen en los cambios y la reorganización del estado durante la Tercera Dinastía de Ur. El lema a-bu- um también significa "festival» y se vinculaba con la realización de libaciones para los difuntos. En acadio, apu puede traducirse como "agujero» o "apertura en el suelo» (CAD A2, p. 201). De ser un objeto específico, en tanto estructura arquitectónica, se habría transformado en una ceremonia conectada con la dimensión mortuoria durante la Tercera Dinastía de 
Ur. Posteriormente, en el período paleo-babilónico, abum/apum se empleó como nombre para uno de los meses del calendario (Cohen, 1993, pp. 259-261). Veamos cómo se da en PDT 1, 541:

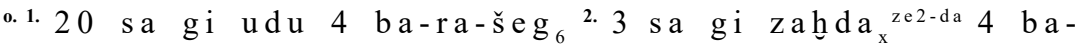

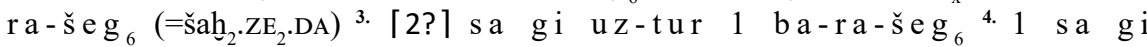

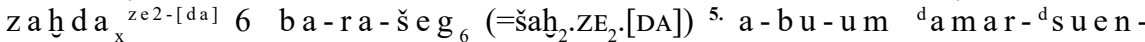

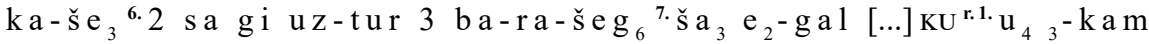
2. $\mathrm{zi}-\mathrm{ga} \mathrm{s}_{3} \mathrm{uri}_{5}{ }^{\mathrm{ki}}-\mathrm{ma}{ }^{3}$. $1 \mathrm{ugal}-\mathrm{bad}-\mathrm{uru}-\mathrm{na} \mathrm{maškim}^{4}$ mu lugalbi in-pa ${ }_{3}^{5}$ iti ki-siki-d nin-a-zu ${ }^{6}$ mu en- ${ }^{d} n a n n a-{ }^{d}$ a mar-d suen-ra $\mathrm{ki}-\mathrm{ag}_{2}$ an-na ba-hun

o. 1. 20 manojos de cañas para cocinar 4 cabras. ${ }^{2}$. 3 manojos de cañas para cocinar 4 cerdos. ${ }^{3 .}{ }^{\text {? }}$ manojos de cañas para cocinar 1 ave-uztur. ${ }^{4}$. 1 manojo de cañas para cocinar 6 cerdos. ${ }^{5}$. Para el festival abum de Ama-Su'ena. 6 . 2 manojos de cañas para

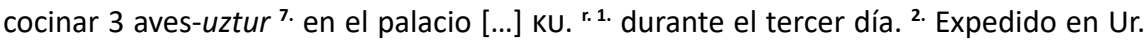
3. Lugal-baduruna, el notario, ${ }^{4}$ juró en el nombre del rey. ${ }^{5}$. Mes: 4. ${ }^{6}$ Año: 9 de AmarSu'ena.

La anterior tablilla, junto a BIN 5, 205 (NBC 1568 = BC 4540), datada en el mes 4 del año 1 de Šū-Su'en y procedente de Umma como la anterior, refiere al abum de Amar-Su'ena:

$$
\begin{aligned}
& \text { o. 1. } 2 \text { kuš GAR }{ }^{2 .} \text { a-bu-um }{ }^{3 . d a m a r-d} \text { duen-ka-š } e_{3}{ }^{!} 4 \cdot \mathrm{du}_{11}-\mathrm{ga} \text { ba- } \\
& \text { a n-kešs } \\
& \text { r.1. ki a-kal-1a-ta }{ }^{2 \cdot k i s ̌ i b ~} 1 u_{2}-b_{a l a-/ s i g}-g^{-g a} \text { ?l 3. iti nesag 4. mu } \\
& { }^{\mathrm{d}} \breve{\mathrm{s}} \mathrm{u}-{ }^{\mathrm{d}} \mathrm{su} \text { en } 1 \mathrm{ug} \text { a } 1 \\
& \text { Sello: }{ }^{1 \cdot} \mid u_{2}-\text { bala-sa }{ }_{6}-g a^{2} \cdot d u b-s a{ }^{3} \cdot d u m u \text { ik- }[\ldots] \\
& \text { o. 1. } 2 \text { (piezas) GAR de cuero }{ }^{2 .} \text { para el festival abum }{ }^{3} \text { de Amar-Su'ena. }{ }^{4} \text {. Duga las }
\end{aligned}
$$

La tablilla precedente describe la celebración del abum en honor a Amar-Su'ena en la misma ciudad de Ur, a la cual se habría enviado una serie de bienes para realizar dicha ceremonia. Sabemos que, durante el Protodinástico III, las tumbas de Ur constituyeron la evidencia monumental más antigua de la Baja Mesopotamia vinculada con enterramientos de elite $y$, en especial, de un sector conectado con la institución del palacio (Woolley, 1934), quienes se habrían apropiado además de las prácticas discursivas asociadas a los templos (Laneri, 2008, p. 204). Los enterratorios, en calidad de espacios evocativos de los muertos, estuvieron vinculados con la vida social de la burocracia estatal, tal como lo señalan los cuencos cerámicos depositados y los tubos para el drenaje que emergían hacia el exterior (Woolley, 1934, p. 224) y se empleaban para realizar libaciones (Cohen, 2005, p. 28), como 
ocurría en el k i - a - n a g . Según Nicola Laneri (2008), en paralelo a la planificación de enterratorios de elite, las costumbres funerarias apuntaron a la materialización ideológica de los nacientes sectores dirigentes vinculados al palacio.

\subsection{Egipto}

Se vinculaba la vida terrena con una proyección hacia una vida póstuma que fuera representativa de los desempeños, estatus y linajes del difunto, siendo reconocidas en los registros parietales de tumbas de la elite, entre otras clases de soportes (papiros y sarcófagos). A propósito de esta clase de monumentos, su distribución en el paisaje regional es representativa per se de cómo los nobles configuraron ese espacio funerario mediante la articulación de lugares elegidos para la construcción de hipogeos en una suerte de «topología social» (Manzi, 2017).

En este caso, analizamos una selección de inscripciones e iconografía registradas en tumbas de nobles. Hasta el presente, fueron contabilizadas 906 estructuras funerarias (Manzi, 2018), de las cuales 86 han sido datadas en la dinastía XVIII de acuerdo con Bertha Porter y Rosalind Moss (1970). Las tumbas eran otorgadas por el faraón a ciertos nobles, quienes obtenían la vida eterna mediante las ofrendas que continuamente debían realizarse a los dioses. En su interior, la decoración parietal representa diversas temáticas, abarcando aspectos de la vida cotidiana y cuestiones transcendentales. Son consideradas las representaciones y menciones de mesas de ofrendas en tanto textualidades que, sin referir a paisajes específicos, son expresiones evocativas del aprovisionamiento material eterno para los dioses y el difunto, las cuales, en función del culto a los muertos, se habrían distribuido en el ámbito de la necrópolis.

Las festividades eran una ocasión para que nobles vivos y muertos participaran de celebraciones con ofrecimiento de bienes (Harrington, 2016). Es así que, en su decoración, se registran escenas en las que el difunto realiza ofrendas a los dioses y en las que puede aparecer ubicado frente a una mesa dotada de alimentos, bebidas y otros objetos.

Se observa que existían dos tipos de ofrendas: las otorgadas por el difunto a los dioses, donde él mismo actuaba como ritualista, y las que el difunto recibía por parte de los sacerdotes. El ritual de ofrendas tenía la función de proporcionar la comida que daba poder a los difuntos para hacer la transición al más allá, donde habitaban los dioses, adquiriendo así una nueva vida como seres divinos y pasando a formar parte de su comunidad en calidad de justificados (Assmann, 2005, p. 58). A su vez, el compartir comida con amigos, colegas y parientes durante las celebraciones era un modo de mantener a los muertos como parte de la comunidad (Robins, 2016, p. 118).

La representación de mesas de ofrendas está presente en la totalidad de las tumbas tebanas de la dinastía XVIII. Estas imágenes operaron de forma mágica, 
conmemorativa y simbólicamente en nombre del difunto y el mundo del que él era parte (Hartwig, 2004, p. 54). El signo $\Theta$ (htp) se asocia con la idea de ofrecer bienes, mediante su relación y/o semejanza con cualquier objeto que se depositaba sobre las mesas. Asociada a esas representaciones y a los objetos apilados sobre ellas, se leía en concordancia la fórmula htp dj nsw u "ofrenda que da el faraón». Esta inscripción activaba el poder de la imagen para proporcionar al difunto un número ilimitado de bienes (Hartwig, 2004, p. 39), resultando que las cantidades indicadas, tanto en forma generalizada como detallada, no tenían correlato con la realidad, sino que poseían funciones simbólicas (Allen, 2006, p. 19; Zinn, 2017, p. 213). La abundancia era representada apilando o agrupando productos del mismo tipo o con más de uno sobre la misma mesa.

En el caso de la tumba de Amenemhat (TT82), otorgada por Tutmosis III, la escena de ofrenda ubicada en la pared norte del pasaje (figura 2) muestra una mesa desbordante de productos alimenticios y, debajo de ella, jarrones que pudieron tener cerveza y aceites; a su derecha, y de frente a la misma, un personaje de pie que levanta una mano y viste pieles, por lo que se lo puede identificar como ritualista y familiar del propietario; del otro lado, se pueden observar al difunto y su esposa, quienes permanecen sentados en actitud receptiva. Sobre esta escena, se ubica una inscripción en la que se pueden identificar tres partes: sobre el ritualista, la fórmula htp dj $n s w$; sobre la mesa, una lista de objetos dispuesta en forma de cuadrícula; y, sobre la pareja de difuntos, algunos de sus títulos.

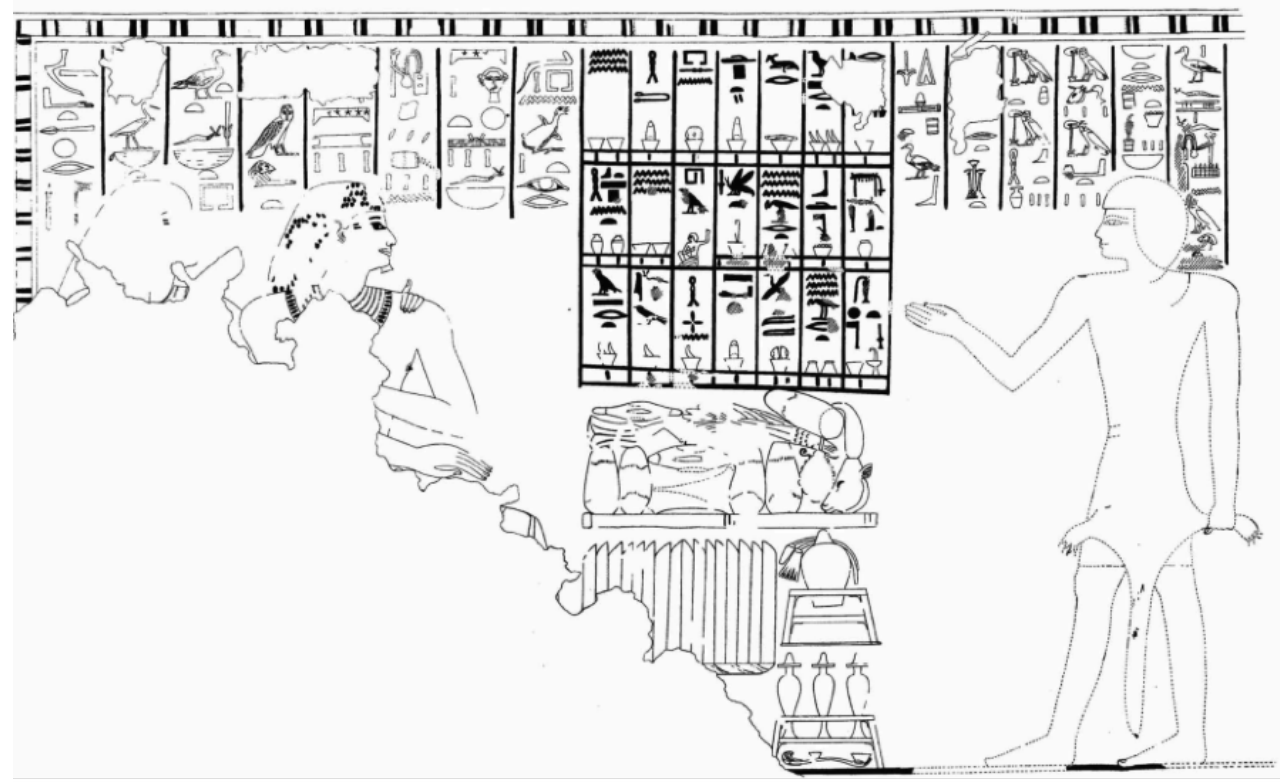

Figura 2. Mesa de ofrendas con representación e inscripciones en la tumba de Amenemhat (TT82) (Davies, 1915, pl. XIV) 
En las fórmulas de ofrenda, se mencionan cifras hiperbólicas de productos de cada tipo, dando cuenta de la discordancia entre las cantidades consignadas en la inscripción y el número de objetos representados. Por este medio, se buscaba simbolizar la abundancia (Ikram, 2008) para así enfatizar el poder económico y social del propietario.

La inscripción sobre el ritualista dice:

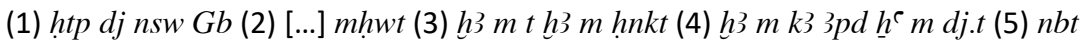
rnpt nb (6) s3.f mrj.f šs n jmn m ḩ3t m3` hrw

Una ofrenda que el Rey da a $G b$ [...] del Bajo Egipto, mil panes, mil cervezas, mil bueyes y gansos, mil de todas las cosas que crecen; su hijo amado de él, el escriba Amenemhat, oh, justificado.

Los productos ofrecidos se detallan en una lista en forma de cuadrícula conformada por tres filas y siete columnas que se ubican sobre la mesa representada, donde cada cuadro contiene una cantidad de productos. Ambas formas de aludir a la ofrenda se refuerzan mutuamente y pueden ser comprendidas tanto por quienes eran capaces de leer jeroglíficos como por quienes no. La inscripción, por su parte, pudo ser recitada ya que posee, en la segunda fila, una exclamación que debía realizarse mientras se mencionaban los productos ofrecidos. La inscripción dice:

\author{
Primera fila: $n w$ (2) - htw - psn -dpty -jw`w -3కrt (2) -jrp (?) \\ Segunda fila: hnkt (2) -mw - h3 hnw -sn bjt -mw ďrt -bd -jrp $m h$ \\ Tercera fila: 3̌rtt-jwf $w r-h w n-\check{s} t-p 3 t(2)-m w d \check{s} r t(2)-k b h$ sntr
}

Primera fila: Dos jarras de agua, un pan $h t w$, un pan psn un pan $d p t y$, un cuenco con pata de res, dos cuencos con carne asada, una vasija con vino

Segunda fila: Dos jarras de cerveza, dos jarras de agua, iOh júbilo!, miel, dos jarras rojas de agua, una cesta con natrón, una vasija con vino del norte

Tercera fila: Un cuenco con carne asada, un cuenco con una pieza grande de carne, un cuenco con costilla asada, un pastel $\varsigma \varsigma^{c}$, un pan $p 3 t$, dos jarras rojas de agua, una libación e incienso.

La cantidad y calidad de los bienes ofrecidos evidencian el vínculo entre las esferas política y divina, donde el faraón y el templo de Amón ejercían un rol gerenciador en el ordenamiento de los espacios funerarios. Dichas instituciones políticas regulaban la provisión de ofrendas mediante el otorgamiento de tumbas y de los bienes requeridos en las celebraciones, sea en forma de productos o permitiendo el acceso a tierras productivas que permanecían en el ámbito de los templos (Haring, 1997, p. 1). La ofrenda resultaba a la vez en nexo con el mundo de los vivos, no sólo por reactivar el vínculo con los difuntos mediante prácticas rituales, sino 
también en las obligaciones que demandaba el beneficio de estar en ese espacio sacralizado.

La continuidad de los rituales estaba garantizada por las donaciones que el propietario realizaba a los templos, de forma tal que su personal quedaba obligado al mantenimiento de la tumba del oferente (Haring, 1997). A propósito, los terrenos de la necrópolis tebana, además de registrar la construcción de tumbas y templos, pudieron ser parte de una extensa zona cultivable que anualmente era inundada por la crecida del Nilo y pertenecía al templo de Amón en Karnak. Estas tierras habrían estado destinadas a producir para proveer en los rituales a los monumentos que se encontraban en ese dominio funerario. Al respecto, en varias tumbas, como por ejemplo en la TT 181, perteneciente a los artesanos Ipuki y Nebamun (Davies, 1925) del reinado de Amenofis III, consta el pedido de estos nobles a los dioses para ser enterrados en la necrópolis:

Que su lugar de descanso en la necrópolis sea aceptable; que tenga una tumba de roca del Oeste; que se digan poderosos hechizos para él en la puerta de su capilla; que adore al dios [cuando] se siente en el lugar de doble justicia, como se hace para alguien que ha hecho bien en la tierra. (Davies, 1925, p. 50).

Una ocasión privilegiada para reactivar las ofrendas en la necrópolis ocurría durante la Bella Fiesta del Valle, momento en el que la estatua de Amón cruzaba el Nilo en una barca ritual para continuar por una vía procesional terrestre su recorrido hasta alcanzar el templo de Hathor en Deir el-Bahari y visitar el templo funerario del faraón oficiante. Las tumbas de los nobles eran parte integrante de esta celebración, ya que podían recibir y ver pasar al dios (Harrington, 2012, p. 14).

Las escenas conmemorativas del evento, registradas dentro de las tumbas, mantenían correspondencia con la orientación geográfica de los templos involucrados en la festividad, estuvieran o no explícitamente representados en la decoración (Pereyra, 2011). La fiesta incluía la concurrencia al lugar de familiares y allegados, siendo esta una de las ocasiones en que se les presentaban sus ofrendas. Conectadas con esta festividad, se encuentran las escenas del banquete, dado que pudieron ser la parte cúlmine de la misma (Manniche, 1997) e incluían también la entrega de alimentos, bebidas, esencias y arreglos florales en honor a los difuntos (Jauhiainen, 2009; Harrington, 2016, pp. 134-136), en conexión con las divinidades (Manniche, 1997, pp. 29-31), a la vez que fueron escenarios para la exhibición pública y el afianzamiento de las relaciones sociales logradas en vida (Pereyra y Manzi, 2014, p. 257).

La participación en el banquete está restringida al parentesco y la adscripción social, enfatizando un patrón jerárquico. En las representaciones, algunos se ubican cerca del propietario de la tumba, en sillas de respaldo alto, y otros, a cierta distancia y arrodillados (Harrington, 2016, p. 161). Estos rituales habrían requerido de variadas tareas, tanto en el momento de la celebración como para su repetición 
en la eternidad. Así cobraba sentido la representación de sacerdotes que acompañaban al difunto, realizaban las matanzas y consagraban las ofrendas, además de quienes las preparaban, de sus portadores y del conjunto de actores sociales que animaban la celebración (Harrington, 2012, p. 118). Los bienes funcionaban también como un indicador de estatus ya que, por ejemplo, la carne, que provenía de animales domesticados o salvajes, requería del funcionamiento de cierta estructura económica al servicio del difunto (Frood, 2010, p. 484). Asimismo, el uso de ciertas ropas, pelucas e insignias distintivas, como el collar shebyu, acentuaban el rol social del propietario de la tumba y su representación evocaba la visita del funcionario a dominios específicos, como el palacio (Pereyra, 2011), enfatizando una actitud receptiva hacia las recompensas, o bien teniéndolas ya en su poder, una vez cedidas por el faraón (figura 3).

Por otro lado, las representaciones del difunto supervisando su patrimonio o realizando el control de trabajos encargados por el faraón eran un justificativo de su derecho a ostentar una porción de territorio divino en la necrópolis (Hartwig, 2004, p. 40). En el caso de Huy (TT40), quien ostentaba, entre otros, los títulos de «Visir de Nubia», "Supervisor del ganado de Amón (en esta tierra de Kush)", "Supervisor de los países de oro de Amón» y «Supervisor de los países de oro del Señor de las Dos Tierras» (Davies, 1926, pp. 4-6) durante el reinado de Tutankamón, las inscripciones e iconografía de su tumba enfatizaban sus logros en el contexto de la expansión

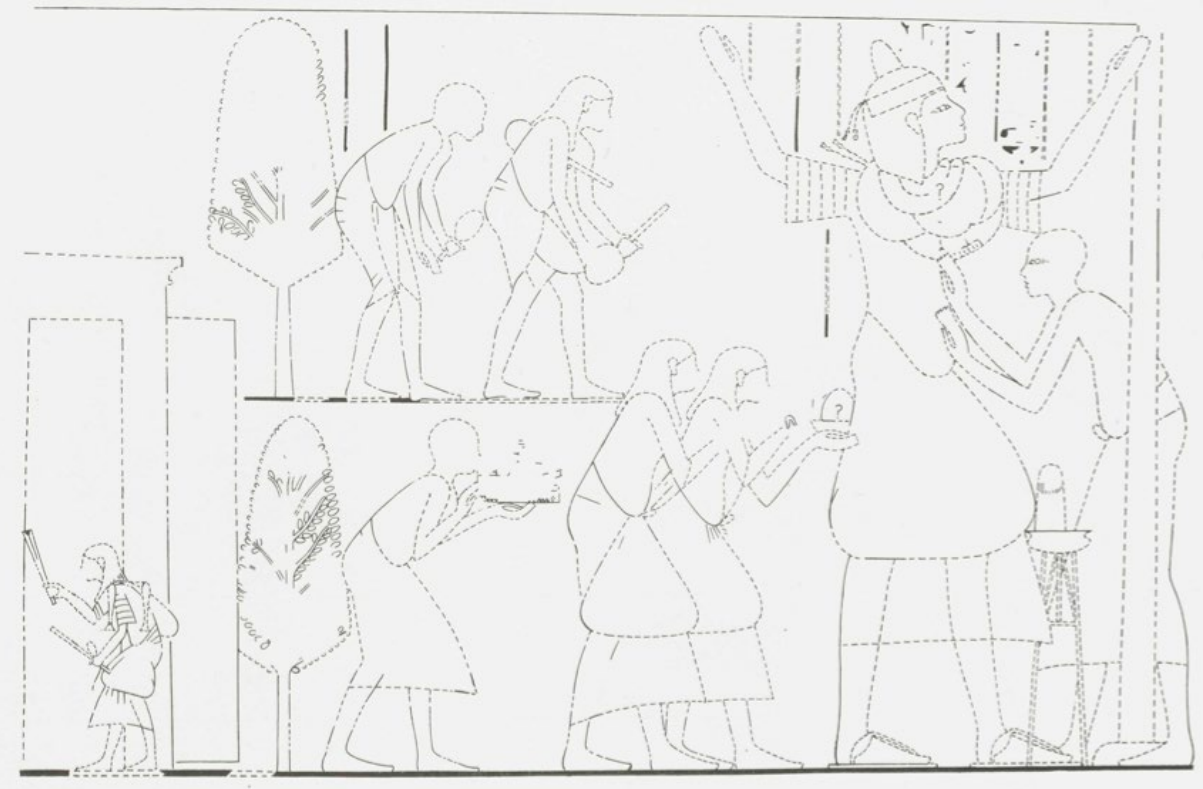

Figura 3. Neferhotep vistiendo collares shebyu. (Davies, 1933, pl. XIII) 


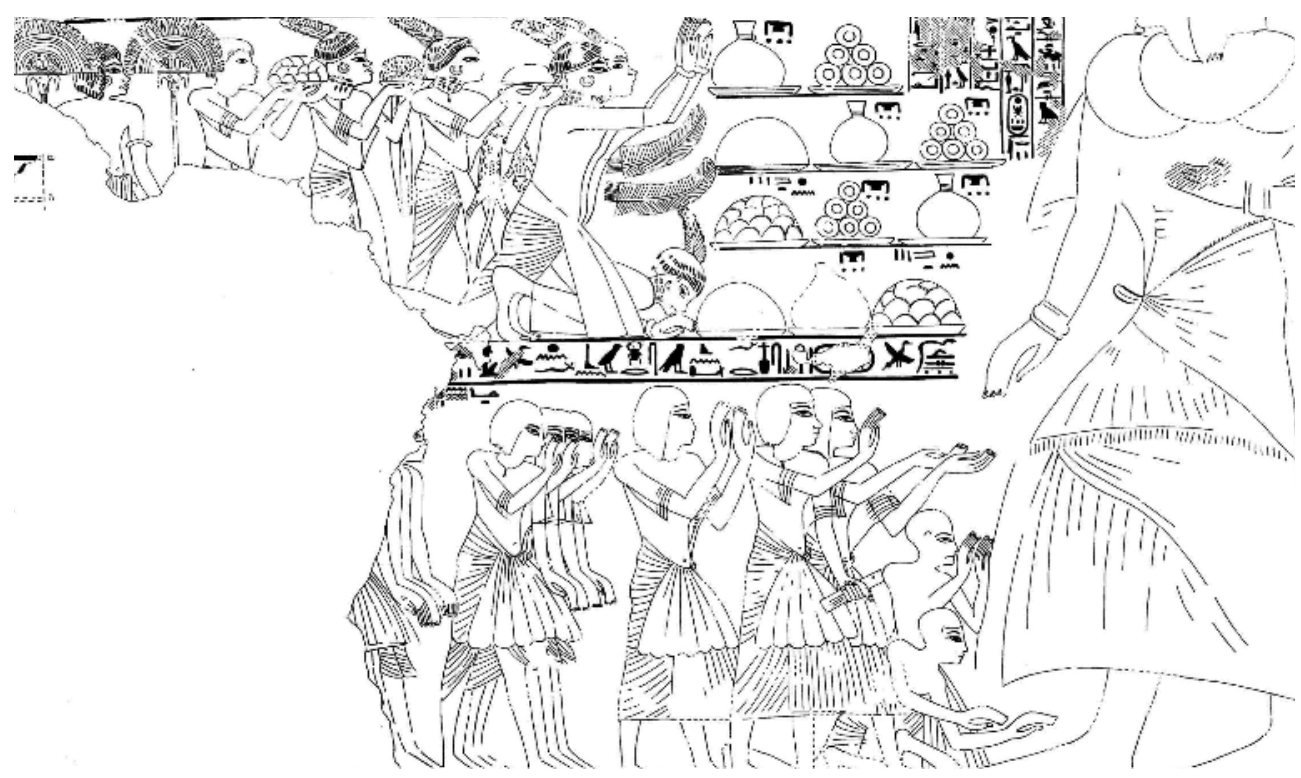

Figura 4. Huy recibiendo tributo extranjero (Davies, 1926, pl. 29)

imperial (figura 4). En una escena, se lo presenta como receptor del tributo nubio en nombre del faraón, indicando que el otorgamiento de su tumba en la necrópolis era un favor merecido, al tiempo que afirmaba su poder personal y el de su linaje dentro del entramado estatal.

Para que un funcionario fuera enterrado en la necrópolis, debía ser capaz de costear la construcción y decoración de una tumba, haberse ganado ese favor, ya sea por su trabajo para el estado como por sus donaciones al templo, además de poseer una proyección familiar que habilitara la manutención de su culto. Estos requisitos estaban relacionados con su identidad laboral y familiar, pero también con los lazos que el propietario mantenía con la realeza y el palacio, y con el templo de Amón y sus dominios, elementos que pueden estar presentes explícita o implícitamente en la decoración de las tumbas tebanas.

\section{AGENTES, ESPACIOS Y PRÁCTICAS EN LA DIMENSIÓN FUNERARIA}

En Mesopotamia, la institucionalización política se configuró en torno a la hegemonía del poder real. En un primer momento, predominó el templo en tanto organización del estado. Pero, hacia fines del III milenio a. C., el entramado político viró hacia el palacio, institución que se apropió de los dispositivos de control, instituyéndose en generador, distribuidor y depositario de la textualidad funeraria. 
La dimensión funeraria estuvo bajo la órbita política de la elite palaciega, siendo la ofrenda una de sus expresiones, en cuanto a la circulación de bienes para la elite. Además, al culto en el k i-a - $\mathrm{n}$ a $\mathrm{g}$ de los reyes fallecidos, se articuló paralelamente el culto a las divinidades tutelares del panteón mesopotámico, las cuales también eran receptoras de ofrendas. De este modo, la burocracia estatal operó en calidad de agente regulador de las prácticas institucionales, tanto en la capital política como a nivel local.

En ese sentido, la dimensión mortuoria, reconstruida a partir de la interpretación de los registros epigráficos, muestra su articulación en torno a un conjunto de espacialidades que sirvieron para la ejecución de ritos y el acaparamiento de bienes bajo la siguiente relación:

\section{Agentes}

dioses, rey, burocracia $\leftrightarrow$ estatal
Espacialidad

capilla funeraria, tumba, templo, palacio
Prácticas

$\leftrightarrow \quad$ ofrenda funeraria

En el caso egipcio, en el transcurso de la dinastía XVIII, la relación «simbiótica» (sensu Kemp, 1972) entre el templo y la realeza y sus elites permite abordar la materialidad funeraria expresada en el otorgamiento y en el programa decorativo de las tumbas, en el que se exhibe el accionar de los agentes intervienes y la inmaterialidad necesaria para garantizar la eficacia de las prácticas rituales. Entre esas prácticas, se destacan los ritos de enterramiento, de culto a la memoria y las festividades oficiales, ocasiones en las que participaban los difuntos y sus parientes vivos encargados de llevar adelante las celebraciones.

La materialidad analizada involucra la tríada conformada por las prácticas, los agentes y la espacialidad para la presentación de bienes, simbolizada mediante la mesa de ofrendas y su provisión como parte de celebraciones periódicas, tales como la Bella Fiesta del Valle. A través del registro epigráfico, resultan evidentes las relaciones que el propietario tenía con el templo de Amón en Karnak y con el palacio, por medio de sus títulos y contando con la participación del faraón, se observa la siguiente relación:

\section{Agentes}

dioses, faraón, elites, sirvientes

\section{Espacialidad}

$\leftrightarrow$

necrópolis, tumba,

templo, palacio

\section{Prácticas}

$\leftrightarrow$

Bella Fiesta del Valle, banquete, ofrenda

En los casos analizados, se observa que la dimensión mortuoria se sustenta en la ocupación efectiva del paisaje, la cual implicó la intervención activa del estado. Se la constata en la distribución de tumbas en vinculación con las instituciones proveedoras de lugares y de bienes, como el templo y el palacio, los cuales mediatizaban 
la intervención de los gobernantes y el sacerdocio. Esto implicó una reactivación terrenal de los bienes entregados bajo la forma de ofrendas que se renovaban con las celebraciones oficiales y el culto a las personas. Para ello, debió darse un despliegue de materialidades, tanto de uso directo como permanente, entre las que se cuentan imágenes y textos alusivos a las ofrendas, a través de los cuales se alcanzaba una síntesis entre la materialidad y la inmaterialidad requeridas por las prácticas funerarias. Asimismo, estas representaciones sellaban a perpetuidad las obligaciones mutuas entre proveedor y receptor, a la vez que resaltaban las capacidades de cada uno dentro de la trama social.

En sus respectivos contextos históricos y culturales, inscripciones e iconografía expresan de modo específico las formas de intervención social de los agentes para el aprovisionamiento y distribución de bienes, tanto en lo concreto como en las proyecciones en el más allá. Mediante la Epigrafía del Paisaje, se reconoce la intervención estatal a favor de las elites, a través de una materialidad, descriptiva y representativa -aspectos semánticos-, plasmada sobre distintos soportes contenedores de inmaterialidades religiosas, míticas y sociales -aspectos sintácticos-, cuya evidencia primaria está constituida por inscripciones administrativas en Mesopotamia y decoración de tumbas en Egipto. Sin embargo, lo más relevante de este enfoque es que todas esas acciones y desempeños tienen una base espacial, puesto que se refieren a lugares y sectores involucrados en las prácticas mortuorias, lo cual remite a un vínculo directo en la creación de paisajes específicos desde esta perspectiva.

Estos paisajes tienen, a su vez, una parte material en la distribución de estructuras funerarias y en la provisión de ofrendas, pero, asimismo, contienen referencias a los actores sociales y a los bienes y cantidades dados por su desempeño y estatus. En este sentido, textos, iconografías y lugares se articulan para dar sentido terrenal y trascendental a la parte existencial de la praxis social.

\section{DISCUSIÓN}

A través de la Epigrafía del Paisaje, analizamos la provisión y almacenamiento de ofrendas funerarias, entendidas como "regalos» o entregas a los individuos, para que estos se beneficiaran de ellas en el más allá y, también, se las presentaran a los dioses para atraer su voluntad.

En este análisis, se destaca que los documentos en sí mismos no refieren necesariamente ni a lugares, ni a sectores del paisaje en los que los agentes sociales se desempeñaron, pero sí se reconoce que el accionar de estos contempló la intervención de instituciones (palacio y templo) y de sus representantes para el otorgamiento de beneficios a miembros de la elite en el marco de celebraciones rituales. Este proceso necesitó de locaciones aptas para el depósito de ofrendas y para la 
realización de las prácticas rituales que requirieron de una organización territorial específica y conformaron paisajes funerarios.

En Mesopotamia, la ofrenda funeraria se vinculó con otras prácticas sociales, en especial, aquellas que los textos administrativos compilaban a través de amplios listados de asignaciones de bienes y de las distintas oficinas que participaban de la regulación de las transacciones. De este modo, resulta imposible separar la materialidad de la escritura y el control ejercido por la burocracia estatal al servicio de la elite dirigente de los reyes de Ur.

En efecto, los archivos cuneiformes de la Tercera Dinastía de Ur refieren de manera integrada y articulada al centro y la periferia del estado con sus respectivas esferas productivas, de circulación y almacenamiento de bienes. Por consiguiente, podemos afirmar que las asignaciones de bienes para la realización del culto mortuorio de los reyes y/o de los miembros de la elite en las capillas mortuorias o $\mathrm{ki}-\mathrm{a}-\mathrm{n}$ a $\mathrm{g}$ se presentan como cantidades concretas en momentos determinados, fijados en el calendario y que podemos reconocer a partir de la datación de las tablillas.

La incrustación que presentan las distintas esferas estatales con la conformación de paisajes funerarios queda claramente representada en la mención del abum, que pudo dar nombre a una festividad evocativa específica de la memoria del muerto, pero, también, y de acuerdo a determinadas interpretaciones, haría referencia a una espacialidad conectada con las capillas funerarias.

En Egipto, la gestión de las ofrendas en manos del estado marca la estrecha relación que existía entre los templos y la realeza, subrayando a que sus tierras y otros recursos se mezclaran y, por tal motivo, en las tumbas, se evocaba el carácter terrenal y religioso al que los difuntos debían responder.

Las tumbas eran otorgadas por el faraón a los nobles como recompensa por su lealtad y servicios al estado, pero, dadas las relaciones que los propietarios mantenían con las deidades locales, estos debían proveerles sustento. A diferencia de los registros presentes en Mesopotamia, en Egipto, las cantidades consignadas en las fórmulas de ofrendas y las representadas apiladas en las mesas no deben verse como registros contables, sino como símbolos de las cantidades y calidades de los productos.

La deidad tebana más importante era Amón y podemos suponer que la necrópolis estaba bajo su jurisdicción económica y religiosa. Esto propiciaba que el templo y el faraón, en cumplimiento de funciones mítico-religiosas, garantizaran la celebración de festividades activadoras del poder divino, como lo fue la Bella Fiesta del Valle. En la producción y circulación de bienes, intervienen las donaciones de las elites, las cuales, en su momento, fueron dadas al faraón o al templo, y que volvían a ellas para el mantenimiento de cultos funerarios privados.

A través de los textos e iconografía funerarios, no siempre es explícita la espacialidad de las acciones. Es así que no constan los otorgamientos de tumbas, ni 
cómo se distribuían las tierras dedicadas a la producción estatal, ni cuáles eran las formas y lugares de almacenamiento de bienes. En cambio, sí se observa la circulación de los mismos, en el sentido de cómo los productos ofrendados fueron parte de un circuito que incluía su cesión y usufructo por parte de las elites-faraón/ templo-elite, como estrategia para garantizar la continuidad de las relaciones entre estos agentes. La contrapartida que mantenía el equilibrio entre las instituciones y los grupos que las mantenían (Haring, 1997, p. 155) era que las primeras se convertían en beneficiarias en tanto estaban encargadas del mantenimiento de los cultos funerarios, de forma tal que lo cedido por el difunto, en determinados momentos de su vida, volvía en forma de ofrenda y de los servicios requeridos por los cultos que garantizaban su vida eterna.

En los rituales funerarios de Mesopotamia, se destacan los miembros de la burocracia estatal y, a través de ella, quienes estaban cercanos al poder político, representado por el palacio. En Egipto, en cambio, tienen un rol preponderante quienes eran beneficiarios de una tumba y formaban parte de los rituales en honor a los difuntos, en cuanto miembros de su linaje y del cortejo fúnebre.

En ambos casos, se constatan por lo menos tres clases de actores sociales. Los miembros de la elite no siempre fueron reconocidos en sus individualidades y vínculos filiales, pero sí como depositarios finales de la circulación de bienes y de las prácticas rituales. Los gobernantes, ocasionalmente identificables, a causa de la mala conservación de los registros, fueron quienes habilitaban los recursos necesarios para hacer efectivas las celebraciones rituales en las que ellos mismos resultaban honrados y exponían devoción hacia los dioses. Las deidades tuvieron una participación activa dado que mediante sus poderes hicieron posible la trascendentalidad de los logros terrenales de quienes las adoraban.

En Mesopotamia, la dotación post mortem de bienes destinados al ritual funerario, así como al culto mortuorio, se efectuaba en lugares específicos, entre los que son reconocidos los enterratorios ( $\mathrm{k}$ - $\mathrm{m}$ a h $)$ y las capillas funerarias $(\mathrm{k} \mathrm{i}-\mathrm{a}-\mathrm{n}$ a $\hat{\mathrm{g}}$ ). En relación a estos, intervienen las ofrendas y equipamientos específicos como, por ejemplo, los tubos de terracota que se elaboraron para conectar el mundo de los muertos y el universo de los vivos. La documentación administrativa refiere a construcciones monumentales erigidas en honor a distintos personajes de la elite. Asimismo, se cuenta con la representación del inframundo y la espacialidad mortuoria consecuente en la literatura sumeria, mediante términos que funcionarían como eufemismos para una realidad desconocida, pero que se pensaba como irreversible y final. Este es el caso de $\mathrm{ki}$ - $\mathrm{m}$ a h , traducido como «tierra excelsa», y que encontramos en los textos administrativos, a diferencia de ki-gal, "gran tierra» o k u r, «tierra desconocida/extranjera» o «montaña», empleadas en la literatura para significar al inframundo.

En Egipto, las ofrendas fusionan la relación del difunto con personas, lugares y deidades. El principal espacio de acción era la propia tumba en conexión con los 
templos. De modo que la vinculación institucional, la proveniencia de lo ofrendado y las cantidades expuestas simbolizaban la capacidad del propietario para mantener su propio culto.

El principal aporte de la Epigrafía del Paisaje no reside en convalidar las comparaciones entre el caso mesopotámico y el egipcio, puesto que cada uno presenta aspectos históricos, culturales y sociales contrastantes. Las principales divergencias se manifiestan en torno a la documentación disponible: $(a)$ en Mesopotamia, predominan las de carácter administrativo-contable e institucional, acordes a un corpus documental «secular» con predominio del palacio; y $(b)$ en Egipto, las del ámbito privado, a pesar de que registran los aportes realizados por las instituciones del templo y el palacio. En los dos estudios de caso, los registros responden a contextos "funerarios», a través de los que se reconocen: (a) las lógicas de la circulación de bienes -a la manera de ofrendas-; $(b)$ el despliegue de una espacialidad vinculada al entorno físico pero también con un mundo imaginado-ficcional; $(c)$ la ejecución de prácticas rituales por agentes del entorno próximo del difunto y con la anuencia de los miembros de la realeza mediante prácticas sociales en espacialidades físicas e imaginadas.

\section{REFERENCIAS BIBLIOGRÁFICAS}

(CAD): Biggs, R. D., Brinkman, J. A., Civil, M., Farber, W., Gelb, I. J., Landsberger, B., Oppenheim, A. L., Reiner, E., Roth, M., y Stolper, M. (Eds.). (1956-2010). The Assyrian Dictionary of the Oriental Institute of the University of Chicago. 21 vols. Chicago, IL: The Oriental Institute of the University of Chicago.

Allen, S. (2006). Miniature and Model Vessels in Ancient Egypt. En M. Barta (Ed.), The Old Kingdom Art and Archaeology: Proceedings of the Conference held in Prague, May 31-June 4, 2004 (pp. 19-24). Prague: Academia.

Andrews, C. (1994). Amulets of Ancient Egypt. Austin, TX: University of Texas Press.

Assmann, J. (1994). Ancient Egypt and the Materiality of the Sign. En H.U. Gumbrecht y K. L. Pfeiffer (Eds.), Materialities of Communication (pp.15-31). Stanford, CA: Stanford University Press.

Assmann, J. (2005). Death and Salvation in Ancient Egypt. Ithaca, NY: Cornell University Press. 
Bailey, G. (2007). Time Perspectives, Palimpsests and the Archaeology of Time. Journal of Anthropological Archaeology, 26(2), pp. 198-223. https://doi. org/10.1016/j.jaa.2006.08.002

Banton, M. (1965). Roles: An Introduction to the Study of Social Relations. London: Tavistock.

Belardi, J. (1992). De lo espacial a lo temporal. Explorando distribuciones de artefactos. Revista de Estudios Regionales, 10, pp. 35-67. https://doi. org/10.1007/978-1-4899-2450-6_3

Binford, L. (1991). When the Going Gets Tough, the Tough Get Going: Nunamiut Local Groups, Camping Patterns and Economic Organization. En C. Gamble y W. Boismier (Eds.), Ethnoarchaeological Approaches to Mobile Campsites: Huntergatherer and Pastoralism Case Studies (pp. 25-137) (Ethnoarchaeological Series 1). An Arbor, MI: International Monigraphs in Prehistory.

Binford, L. (1992). Seeing the Present and Interpreting the Past and Keeping Things Straight. En J. Rossignol y A. Wandsnider (Eds.), Space, Time, and Archaeological Landscapes (pp. 43-64). New York, NY: Plenum Press.

Binford, L. (2001). Constructing Frames of Reference: An Analytical Method for Archaeological Theory Building Using Hunter-Gatherer and Environmental Data Sets. Berkeley, CA: University of California Press.

Blanton, R., Feinman, G., Kowalewski, S., y Peregrine, P. (1996). A Dual-Processual Theory for the Evolution of Mesoamerican Civilization. Current Anthropology, 37(1), pp. 1-14. https://doi.org/10.1086/204471

Butzer, K. (1982). Archaeology as Human Ecology: Method and Theory for a Contextual Approach. Cambridge: Cambridge University Press. https://doi. org/10.1017/CBO9780511558245

Cabrera, R. (2017). La inter-textualidad y la inter-materialidad de los objetos. La "ofrenda funeraria» en la tensión entre cultura material y evidencia epigráfica entre el Dinástico Temprano IIIB y la época neo-sumeria (Baja Mesopotamia, c. 2600-2100 a.C.). Sociedades precapitalistas. Revista de Historia Social, 7(1): e020. https://doi.org/10.24215/22505121e020

Cabrera, R. (2019a). Entre cuñas, tablillas y escribas: la materialidad de los paisajes funerarios en Mesopotamia durante la Tercera Dinastía de Ur. Revista del 
Museo de Antropología, 12(2), pp. 7-22. https://doi.org/10.31048/1852.4826. v12.n2.23526

Cabrera, R. (2019b). Materialidad, cosmografía y an-ki (universo) en la antigua Mesopotamia. Avá. Revista de Antropología, 35, pp. 25-54.

Cabrera, R. (2020). La (in)materialidad del Inframundo y su (re)presentación en la antigua Mesopotamia: una interpretación del repertorio iconográfico y las fuentes documentales. Mundo de Antes. Revista del Instituto de Arqueología y Museo, 14(1), pp. 141-173.

Cabrera, R., y Manzi, L. (2018). Materialidad y signo lingüístico en Egiptología y Asiriología: diálogos entre pensamiento concreto y lógica de lo abstracto. Ponencia presentada en las III Conferencia de Egiptología Latinoamericana. Buenos Aires: IMHICIHU, CONICET.

Cohen, A. (2005). Death Rituals, Ideology, and the Development of Early Mesopotamian Kingship: Toward a New Understanding of Iraq's Royal Cementery of Ur (Ancient Magic and Divination 7). Leiden: Brill.

Cohen, M. E. (1993). The Cultic Calendars of the Ancient Near East. Bethesda, MD: CDL Press.

Criado Boado, F. (1993). Límites y posibilidades de la Arqueología del Paisaje. Spal. Revista de Prehistoria y Arqueología, 2, pp. 9-55. https://doi.org/10.12795/ spal.1993.i2.01

Criado Boado, F. (1999). Del terreno al espacio: planteamientos y perspectivas para la Arqueología del Paisaje. Cadernos de Arqueoloxía e Patrimonio, 6, pp. 1-82.

Criado Boado, F. (2015). Archaeologies of Space: An Inquiry into Modes of Existence of Xscapes. En K. Kristianse, L. Šmejda y J. Turek (Eds.), Paradigm Found. Archaeological Theory Present, Past and Future. Essays in Honour of Evžen Neustupný (pp. 61-83). Oxford/Philadelphia, PA: Oxbow Books. https://doi. org/10.2307/j.ctvh1dpc1.9

Davies, N. de G., y Gardiner, A. (1915). The Tomb of Amenemhēt (No. 82). London: Egypt Exploration Society. 
Davies, N. de G. (1925). The Tomb of Two Sculptors at Thebes: With Plates in Color by Norman de Garis Davies, Nina de G. Davies, HR Hopgood and Charles K. Wilkinson. New York, NY: Metropolitan Museum of Art.

Davies, N. de G. (1933). The Tomb of Neferhotep at Thebes (Vols. 1 \& 2) (Egyptian Expedition 9). New York, NY: Metropolitan Museum of Art.

Davies, N. de G., y Gardiner, A. (1926). The Tomb of Huy, Viceroy of Nubia in the Reign of Tut'ankhamūn (no. 40) Copied in Line and Colour by Nina de Garis Davies, and with Explanatory Text by Alan H. Gardiner, etc. London: Egypt Exploration Society.

Descola, P. (2005). Par-delà nature et culture. Paris: Gallimard.

Dincauze, D. (1987). Strategies for Paleoenvironmental Reconstruction in Archaeology. En M. Schiffer (Ed.), Advances in Archeological Method and Theory (pp. 255-296) (Vol. 11). Orlando, FL: Academic Press. https://doi.org/10.1016/ B978-0-12-003111-5.50008-7

Dunnell, R. (1992). The Notion Site. En J. Rossignol y L. Wandsnider (Eds.), Space, Time, and Archaeological Landscapes: Interdisciplinary Contributions to Archaeology (pp. 21-41). New York, NY: Plenum Press. https://doi.org/10.1007/978-1-48992450-6_2

Ebert, J. (1992). Distributional Archaeology. Albuquerque, NM: University of New Mexico Press.

Eyre, C. (2018). The Material Authority of Written Texts in Pharaonic Egypt. En F. A. J. Hoogendijk y S. M. T. van Gompel (Eds.), The Materiality of Texts from Ancient Egypt: New Approaches to the Study of Textual Material from the Early Pharaonic to the Late Antique Period (pp. 1-11). Leiden/Boston, MA: Brill. https://doi.org/10.1163/9789004375277_002

Feinman, G. (1995). The Emergence of Inequality. A Focus on Strategies and Processes. En D. Price y G. Feinman (Eds.), Foundations of Social Inequality (pp. 255-274). New York, NY: Plenum. https://doi.org/10.1007/978-1-4899-12893_10

Firth, R. (1961 [1938]). Human Types: An Introduction to Social Anthropology (Mentor Book 423). New York, NY: The New American Library. 
Foley, R. (1981). Off Site Archaeology: an Alternative Approach for the Short Sited. En I. Hodder, N. Hammond y G. Issac G (Eds.), Pattern in the Past: Essays in Honour of David Clarke (pp. 157-183). Cambridge: Cambridge University Press.

Franke, J. A. (1977). Presentation Seals of the Ur III/Isin Larsa Period. En M. Gibson y R. D. Biggs (Eds.), Seals and Sealing in the Ancient Near East (pp. 61-66) (Bibliotheca Mesopotamica 6). Malibu, CA: Undena Publications.

Frood, E. (2010). Social Structure and Daily Life: Pharaonic. En A. Lloyd (Ed.), A Companion to Ancient Egypt I (pp. 469-490). Oxford: Wiley-Blackwell. https:// doi.org/10.1002/9781444320053.ch25

Gamble, C., y Soffer, O. (1990). Introduction. Pleistocene Polyphony: The Diversity of Human Adaptations at the Last Glacial Maximum. En O. Soffer y C. Gamble (Eds.), The World at 18,000 B.P. (Vol. 1) (pp. 1-23). London: Unwin Hyman.

Gardiner, A. (1957 [1927]). Egyptian Grammar: Being an Introduction to the Study of Hieroglyphs. Oxford: Griffith Institute, Ashmolean Museum.

Haring, B. (1997). Divine Households: Administrative and Economic Aspects of the New Kingdom Royal Memorial Temples in Western Thebes (Egyptologische Uitgaven 12). Leiden: Nederlands Institut Voor Het Nabue Oosten.

Harrington, N. (2012). Living with the Dead: Ancestor Worship and Mortuary Ritual in Ancient Egypt. Oxford: Oxbow Books.

Harrington, N. (2016). The Eighteenth Dynasty Egyptian Banquet: Ideals and Realities. En C. Draycott y M. Stamatopoulou (Eds.), Dining and Death: Interdisciplinary Perspectives on the "Funerary Banquet» in Art, Burial and Belief (pp. 129-172) (Colloquia Antiqua 16). Leuven Peeters. https://doi.org/10.2307/j.ctvh1ds21

Hartwig, M. (2004). Tomb painting and identity in ancient Thebes: 1419-1372 BCE. Turnhout: Brepols.

Heidegger, M. (1967 [1927]). Sein und Zeit. Tübingen: Max Niemeyer Verlag.

Hernando Gonzalo, A. (1999). El espacio no es necesariamente un lugar: en torno al concepto de espacio y a sus implicaciones en el estudio de la Prehistoria. Arqueología espacial, 21, pp. 7-28. 
Ikram, S. (2008). Food and Funerals. Sustaining the Dead for Eternity. Polish Archaeology in the Mediterranean, 20, pp. 361-371.

Jagersma, B. (2007). The Calendar of the Funerary Cult in Ancient Lagash. Bibliotheca Orientalis, 64, pp. 289-307. https://doi.org/10.2143/BIOR.64.3.2023945

Jauhiainen, H. (2009). «Do Not Celebrate Your Feast without Your Neighbours». A Study of References to Feasts and Festivals in Non-Literary Documents from Ramesside Period Deir el-Medina. Helsinki: Helsinki University Print.

Kemp, B. (1972). Temple and Town in Ancient Egypt. En P. Ucko P, R. Tringham y G. Dimbleby (Eds.), Man, Settlement and Urbanism. Proceedings of a Meeting of the Research Seminar in Archaeology and Related Subjects Held at the Institute of Archaeology, London University (pp. 657-680). London: Duckbacks.

Laneri, N. (2008). Texts in Context: Praxis and Power of Funerary Rituals among Elites in Ancient Mesopotamia. En L. Fogelin (Ed.), Religion, Archaeology, and the Material World (pp. 196-215). Carbondale, IL: Center for Archaeological Investigations, Southern Illinois University Carbondale.

Lévi-Strauss, C. (1962). La pensée sauvage. Paris: Plon.

Manniche, L. (1997). Reflections on the Banquet Scene. En R. Tefnin (Ed.), La peinture Égyptienne ancienne: un monde de signes à préserver. Actes du Colloque International de Bruxelles Avril 1994 (pp. 29-36). Bruxelles: Fondation Égyptologique Reine Élisabeth.

Manzi, L. (2012). La jerarquización del espacio a través de la distribución de tumbas privadas en Tebas Occidental, Egipto. En L. Araújo y J. Sales (Eds.), Novos Trabalhos de Egiptologia Ibérica (Vol. 1) (pp. 637-655). Lisboa: Instituto Oriental e Centro de História da Faculdade de Letras da Universidade de Lisboa.

Manzi, L. (2016). Monumentalización y evocación en el paisaje de Tebas Occidental, Egipto. Revista Mundo Antigo. Dossiê Egiptologia, 5(9), pp. 191-205.

Manzi, L. (2017a). Patrones espaciales en la resolución de palimpsestos en el oeste tebano, Egipto. En A. Brancaglion y G. Chapot (Eds.), Semana de Egiptologia do Museu Nacional (SEMNA) (Estudos de Egiptologia IV) (pp. 51-60). Rio de Janeiro: Seshat- Laboratório de Egiptologia do Museu Nacional Editora e Klínē. 
Manzi, L. (2017b). Topología social: actores y acciones en el paisaje tebano. En L. Burgos Bernal, A. Pérez Largacha e I Vivas Sainz (Eds.), Actas del V Congreso Ibérico de Egiptología, Cuenca, 9 a 12 de marzo de 2015 (pp. 589-601) (Colección Estudios 157). Cuenca: Ediciones de la Universidad de Castilla-La Mancha.

Manzi, L. (2018). Personas y lugares en el paisaje de Tebas Occidental, Egipto. En A. Brancaglion y G. Chapot (Eds.), Semana de Egiptologia do Museu Nacional (SEMNA) (pp. 90-105) (Estudos de Egiptologia V). Rio de Janeiro: SeshatLaboratório de Egiptologia do Museu Nacional Editora e Klínē.

Manzi, L., y Pereyra, M. V. (2014). El banquete funerario y la Bella Fiesta del Valle en Tebas Occidental. NEARCO. Revista Eletrônica de Antiguidade, 7(1), pp. 238259.

Mayr, R. H., y Owen, D. I. (2004). The Royal Gift Seal in the Ur III Period. En H. Waetzoldt (Ed.), Von Sumer nach Ebla und zurück. Festschrift-Giovanni Pettinato zum 27. September 1999 gewidmet von Freunden, Kollegen und Schülern (pp.145-174) (Heidelberger Studien zum Alten Orient 9). Heidelberg: Heidelberger Orientverlag.

Miller, D. (1987). Material Culture and Mass Consumption. Oxford: Blackwell.

Miller, D. (2005). Materiality. An Introduction. En D. Miller (Ed.), Materiality (pp. 1-50). (Politics, History, and Culture). Durham/London: Duke University Press.

Molina, M. (2008). The Corpus of Neo-Sumerian Tablets: an Overview. En S. J. Garfinkle y Johnson (Eds.), The Growth of an Early State in Mesopotamia: Studies in Ur III Administration (pp. 19-53) (Biblioteca del Próximo Oriente Antiguo 5). Madrid: Consejo Superior de Investigaciones Científicas.

Molina, M. (2016). Archives and Bookkeeping in Southern Mesopotamia during the Ur III Period. Archéologie de la comptabilité. Culture matérielle des pratiques comptables au Proche-Orient ancien, 8. http://journals.openedition.org/ comptabilites/1980

Molina, M. (2019). Sumerian Judicial Procedures against Tomb Robbers. En G. Chambon, M. Guichard \& A.-I. Langlois (Eds.), De L'argile au numérique. Mélanges assyriologiques en l'honneur de Dominique Charpin, Tomo 2 (pp. 693-712) (Publications de L'Institut du Proche-Orient Ancien du Collège de France 3). Leuven/Paris/Bristol: Peeters. 
Molina, M. (2020). The Looting of Ur III Tablets after the Gulf Wars. En W. Sommerfeld (Ed.), Dealing with Antiquity: Past, Present \& Future. Proceedings of the $63^{\text {rd }}$ Rencontre Assyriologique Internationale held at Marburg (pp. 323-352) (Alter Orient und Altes Testament. Veröffentlichungen zur Kultur und Geschichte des Alten Orients und des Alten Testaments 460). Münster: Ugarit-Verlag.

Orejas, A. (1991). Arqueología del Paisaje: historia, problemas y perspectivas. Archivo Español de Arqueología, 64(163-164), pp. 191-230. https://doi. org/10.3989/aespa.1991.v64.503

Orejas, A. (1995). Arqueología del Paisaje: de la reflexión a la planificación. Archivo Español de Arqueología, 68(171-172), pp. 215-224. https://doi.org/10.3989/ aespa.1995.v68.423

Parkinson, R. (1991). Voices from Ancient Egypt. An Anthology of Middle Kingdom Writings. London: British Museum Press.

Pereyra, M. V. (2011). El gran templo de Amón en la tumba de Neferhotep TT49. Revista del Instituto de Historia Antigua Oriental, 17, pp. 17-26. https://doi. org/10.34096/rihao.n17.170

Pereyra, M. V. (2012). El palacio real en el umbral del Más Allá. En L. Araújo y J. Sales (Eds.), Novos Trabalhos de Egiptologia Ibérica (Vol. 1) (pp. 871-883). Lisboa: Instituto Oriental e Centro de História da Faculdade de Letras da Universidade de Lisboa.

Piquette, K. E., y Whitehouse, R. D. (2013). Introduction: Developing an Approach to Writing as Material Practice. En K. E. Piquette y R. D. Whitehouse (Eds.), Writing as Material Practice: Substance, Surface and Medium (pp.1-13). London: Ubiquity Press. https://doi.org/10.5334/bai.a

Porter, A. (2002). Communities in Conflict: Death and the Contest for Social Order in the Euphrates River Valley. Near Eastern Archaeology, 65(3), pp. 156-173. https://doi.org/10.2307/3210881

Porter, A. (2007-2008). Evocative Topography: Experience, Time and Politics in a Landscape of Death. En G. Bartoloni y M. G. Benedettini (Eds.), Sepolti tra i vivi. Evidenza ed interpretazione di contesti funerari in abitato. Atti del Convegno Internazionale, Roma, 26-29 Aprile 2006 (pp. 71-80). (Scienze dell'Antichità 14/1). Roma: Quasar. 
Porter, B., y Moss, R. (1970). Topographical Bibliography of Ancient Egyptian Hieroglyphic Texts, Reliefs, and Paintings. I. The Theban Necropolis, Part 1. Private Tombs. Oxford: Griffith Institute, Ashmolean Institute.

Rede, M. (2004). Práticas funerárias, culto aos ancestrais e transmissão do patrimônio familiar na antiga Mesopotâmia. Revista do Museu de Arqueologia e Etnologia, 14, pp. 117-138. https://doi.org/10.11606/issn.2448-1750. revmae.2004.89661

Rede, M. (2007). Família e patrimônio na antiga Mesopotâmia. Rio de Janeiro: Mauad X.

Robins, G. (2016). Meals for the Dead: the Image of the Deceased Seated before a Table of Offerings in Ancient Egyptian Art. En C. Draycott y M. Stamatopoulou (Eds.), Dining and Death: Interdisciplinary Perspectives on the «Funerary Banquet» in Art, Burial and Belief (pp. 111-127) (Colloquia Antiqua 16). Leuven: Peeters.

Rodríguez Mayorgas, A. (2010). Arqueología de la palabra: oralidad y escritura en el mundo antiguo. Barcelona: Bellaterra.

Sence, G. (2007). Dur-Sharrukin: le portrait de Sargon II. Revue des Études Anciennes, 109(2), pp. 429-447.

Steinkeller, P. (2004). The Function of Written Documentation in the Administrative Praxis of Early Babylonia. En M. Hudson y C. Wunsch (Eds.), Creating Economic Order: Record-Keeping, Standardization, and the Development of Accounting in the Ancient Near East. A Colloquium held at the British Museum, November 2000 (pp. 65-88) (International Scholars Conference on Ancient Near Eastern Economies 4). Bethesda, MD: CDL.

Steinkeller, P. (2008). Joys of Cooking in Ur III Babylonia. In: Michalowski P (ed) On the Third Dynasty of Ur: Studies in Honor of Marcel Sigrist (pp. 185-192) (The Journal of Cuneiform Studies. Supplemental Series 1). Boston, MA: The American Schools of Oriental Research.

Thomas, D. (1975). Nonsite Sampling in Archaeology: Up the Creek Without a Site? En W. James (Ed.), Sampling in Archaeology (pp. 61-83). Tucson, AZ: The University of Arizona Press. 
Tilley, C. (Ed.). (1990). Reading Material Culture: Structuralism, Hermeneutics, and Post-structuralism. Oxford: Basil Blackwell Ltd.

Tsouparopoulou, C. (2008). The Material Face of Bureaucracy: Writing, Sealing and Archiving Tablets for the Ur III State at Drehem (Tesis inédita de doctorado). University of Cambridge, Inglaterra.

Tsouparopoulou, C. (2013). Reflections on Paratextual Markers and Graphic Devices in Ur III Administrative Documents. Textual Cultures, 8(2), pp. 1-14. https://doi. org/10.14434/tc.v8i2.13276

Tsouparopoulou, C. (2015). Spreading the Royal Word: The (Im)Materiality of Communication in Early Mesopotamia. En S. Enderwitz y R. Sauer (Eds.), Communication and Materiality in Pre-Modern Societies (pp. 7-23) (Materiale Textkulturen 8). Berlin/New York, NY: Walter de Gruyter. https://doi. org/10.1515/9783110371758-003

Tsouparopoulou, C. (2016). Deconstructing Textuality, Reconstructing Materiality. En T. Balke y C. Tsouparopoulou (Eds.), Materiality of Writing in Early Mesopotamia (pp. 257-275) (Materiale Textkulturen 13). Berlin/New York, NY: Walter de Gruyter. https://doi.org/10.1515/9783110459630-012

van Essche-Merchez, E. (1992). La syntaxe formelle des reliefs et de la grande inscription de l'an 8 de Ramsès III à Médinet Habou. Chronique d'Egypte, 67(134), pp. 211-239. https://doi.org/10.1484/J.CDE.2.308904.

Wilkinson, R. (1994). Symbol \& Magic in Egyptian Art. London/New York, NY: Thames \& Hudson.

Winter, I.J. (1986). The King and the Cup. En M. Kelly-Buccellati, P. Matthiae y M. van Loon (Eds.), Insight Through Images: Studies in Honor of Edith Porada (pp. 253-268) (Bibliotheca Mesopotamica 21). Malibu, CA: Undena Publications.

Winter, I.J. (1987). Legitimation of Authority Through Image and Legend: Seals Belonging to Officials in the Administrative Bureaucracy of the Ur III State. En M. Gibson y R.D. Biggs (Eds.), The Organization of Power: Aspects of Bureaucracy in the Ancient Near East (pp. 69-116) (Studies in Ancient Oriental Civilization 46). Chicago, IL: The Oriental Institute of the University of Chicago. 
Woolley, L. (1934). The Royal Cemetery. A report on the Predynastic and Sargonic Graves Excavated between 1926 y 1931 (Ur Excavations 2). London/Philadelphia, PA: Trustees of the British Museum and of the Museum of University of Pennsylvania.

Zinn, K. (2017). Lacklustre Offering Plates? Symbolic Food Consumption, Ritual and Representations in Ancient Egyptian Funerary Culture. En L. Steel y K. Zinn (Eds.), Exploring the materiality of Food 'Stuffs': Transformations, Symbolic Consumption and Embodiments (pp. 205225). London: Routledge. 